\title{
Current Emotion Research in Social Psychology: Thinking About Emotions and Other People
}

\author{
Brian Parkinson \\ Department of Experimental Psychology, University of Oxford, UK
}

Antony S. R. Manstead

School of Psychology, Cardiff University, UK

\begin{abstract}
This article discusses contemporary social psychological approaches to (a) the social relations and appraisals associated with specific emotions; (b) other people's impact on appraisal processes; (c) effects of emotion on other people; and (d) interpersonal emotion regulation. We argue that single-minded cognitive perspectives restrict our understanding of interpersonal and grouprelated emotional processes, and that new methodologies addressing real-time interpersonal and group processes present promising opportunities for future progress.
\end{abstract}

\section{Keywords}

interpersonal emotion regulation, schadenfreude, social appraisal, social psychology

What happens in most psychological experiments? A participant sits at a monitor or lies in a scanner. An experimenter delivers instructions and presents stimuli or other information (some of which may relate to emotion). The participant makes judgements, performs mental tasks, or passively registers what is presented. The experimenter takes measures relating to the participant's cognition, affect, or behavior.

You might think that social psychological research works differently. Because social psychology is concerned with how people think, feel, and behave in relation to other people (e.g., Allport, 1954), studying two or more people interacting (rather than one person acting or reacting) might seem the most obvious source of relevant evidence. However, the desire for a distinctive disciplinary identity (coupled with the associated division of academic labor) means that most social psychologists see their task as investigating the mental operations that influence (social) behavior. Presenting an individual with specific instructions and information in controlled settings permits such investigation using tried and tested methods from cognitive psychology and neuropsychology. From this perspective, including one or more other people only complicates matters.
Although cognitive and neuroscientific approaches to social psychology continue to yield important findings, their potential limitations have been addressed by other social psychologists who locate our discipline more broadly within the social and human sciences and exploit synergies with sociological, anthropological, geographical, or historical traditions (e.g., Brown \& Stenner, 2009; Wetherell, 2012). Indeed, perhaps individuals attain individuality partly as a function of broader social processes (e.g., Mead, 1934; Sampson, 2008).

What about social psychological research into emotion? A focus on private responses is consistent with the prevalent view that emotions are first and foremost reactive mental states, even if the episodes and events to which these states relate typically unfold in a web of dynamic social interactions and relationships (embedded within cultural institutions and practices). Thus, research participants are again often passive recipients of information about social events rather than actors engaging with other people in real-world, real-time contexts. For ethical as well as practical reasons, experiments where participants interact directly with someone else (e.g., Latané \& Darley, 1968; Schachter \& Singer, 1962) fell out of favor around the 
1970s (with some notable exceptions, e.g., Reicher \& Haslam, 2006; Zadro et al., 2004). Historically, naturalistic studies have been relatively infrequent in mainstream quantitative social psychology, but are beginning to attract more interest as mobile recording technologies (e.g., Cunningham, Dunfield, \& Stillman, 2013) and more sophisticated techniques for analysis of multivariate, dyadic, and time-based data (e.g., Butler, 2011) become available. Studies of how emotions are actively formulated in ongoing discourse (e.g., Edwards, 1999) have generally had limited impact on the mainstream, despite the insights that they offer.

In short, most social psychological research into emotion continues to be concerned with how emotions affect, and are affected by perceptual and cognitive processes operating within an individual mental system. Investigating these intrapsychic processes helps explain some aspects of how emotions operate in the social world, but can never tell the whole story (see also Fischer \& van Kleef, 2010). In this article, we discuss some of the potentially interesting findings of such studies and suggest ways in which they might be extended by investigating interactions between people.

Our coverage is necessarily selective. Most current social psychological research has some affective dimension, even when emotion is not its central focus (Parrott, 2001). We cannot hope to capture fully the ever-growing scale and diversity of the literature here. Because we believe that social psychology should directly address social causes, effects, and functions of emotion, we exclude ostensibly social psychological studies whose main focus is on individuals in relation to nonsocial situations (e.g., studies of how affect influences cognition, e.g., Worthy, Byrne, \& Fields, 2014; and autonomic differentiation, e.g., Kreibig, 2010). ${ }^{1}$ Instead, we focus on examples of research that address emotion's relation to its local social context, ${ }^{2}$ even if this context is presented only as information, and participants' opportunities for direct engagement are tightly controlled.

Social factors are implicated in emotion in many ways and at many levels. First, the objects at which emotions are directed often have a social dimension. For example, we may get angry because someone else has insulted us, or feel schadenfreude when a rival suffers defeat. Second, our appraisal of these emotional objects may depend on social factors. For example, we may appreciate more fully the seriousness of an insult in the presence of someone who expresses shock, and we may experience stronger schadenfreude in the presence of other people who share our antagonism. Third, our expression of emotion may bring about various effects on other people. For example, our anger may solicit guilt or counteranger from the person who has insulted us, and our schadenfreude may bring us closer to those who share our rivalry. Fourth, we may regulate our emotions because we are concerned about their impact on others. For example, we may suppress our anger to maintain a positive relationship with the person insulting us, and we may exaggerate our schadenfreude to align ourselves with other people who share our rivalry. The following sections consider recent research in these four areas.

\section{Emotions With Social Objects}

For many theorists, emotions can be distinguished by reference to the specific nature of the person's evaluative orientation to an intentional object. For example, influential research by C. A. Smith and Ellsworth (1985) sought to identify the characteristic appraisal dimensions associated with a wide range of emotions in order to develop a systematic generative grammar of emotion differentiation (see Tong, 2015, for a recent example of such research).

For obvious reasons, social psychologists are particularly interested in emotions that are directly related to social objects (i.e., social emotions; Hareli \& Parkinson, 2008). Inspired by the appraisal approach, several researchers have developed more fine-grained analyses of the appraisals of social relations that permit us to distinguish pairs of related social emotions from one another (e.g., disgust and anger, Giner-Sorolla, 2012; envy and jealousy, Parrott \& Smith, 1993; anger and contempt, Fischer \& Roseman, 2007; shame and guilt, Tangney \& Dearing, 2002).

Other researchers tighten their focus still further by investigating specific social emotions in their own right. These emotions often carry positive or negative consequences for social life, and their selection is often motivated by political or moral concerns. The ultimate aim is to understand the emotional sources of social harmony or suffering, injustice and strife, so that interventions may be developed to make life better. For example, social psychologists have studied compassion (e.g., Goetz, Keltner, \& Simon-Thomas, 2010), gratitude (Algoe, 2012; Jia, Tong, \& Lee, 2014), and intergroup anxiety (Stephan, 2014).

This section focuses on recent social psychological studies of an emotion that is specifically defined in terms of the social object that it takes (Fischer, 2014). Schadenfreude is a German word describing the pleasure (Freude $=$ joy) that people take in someone else's misfortune (Schaden $=$ damage or harm). There is a clear social dimension to schadenfreude experiences since they require a target person who is suffering (target) and another individual who takes pleasure in the target's suffering. However, contact between these people need not be direct and schadenfreude can be induced experimentally by presenting participants with descriptions of someone else's behavior or clips from "humilitainment" TV shows (see Booker \& Waite, 2005; R. H. Smith, 2013) such as I'm a Celebrity, Get Me Out of Here!, or the audition stages of Pop Idol (van Dijk, Ouwerkerk, van Koningsbruggen, \& Wesseling, 2012).

Most appraisal research focuses on how people appraise what is happening immediately before or during emotional experiences. Appraisal researchers usually pay relatively less attention to the events leading to these emotion-specific appraisal patterns. However, given that appraisals concern relational meanings (e.g., Lazarus, 1991) it is important to understand the world to which appraisers orient as well as their orientation itself. By intensively investigating an individual emotion related to a particular kind of social event, schadenfreude researchers are well-placed to generate insights concerning its social-relational context. 
Van Dijk and Ouwerkerk (2014) distinguished three concerns explaining why a person may find another person's negative outcome satisfying: envying someone else (e.g., R. H. Smith \& Kim, 2007), feeling that they deserve to suffer (e.g., Feather, Wenzel, \& McKee, 2012), and feeling inferior to them. Regarding the third of these concerns, van Dijk, Ouwerkerk, Wesseling, and van Koningsbruggen (2011) showed that people report stronger schadenfreude in response to the suffering of someone who represents a specific threat to their self-esteem. Participants with low self-esteem who were not given an opportunity to self-affirm reported the highest levels of schadenfreude when a high-performing other person suffered a misfortune, and this effect was mediated by self-threat. These findings suggest that one function of schadenfreude is to defend self-esteem when confronted by unfavorable social comparisons. The other person's suffering reduces the perceived status discrepancy and helps to alleviate the pain of inferiority.

These interpersonal dynamics also extend to intergroup interactions. For example, when a soccer team that you support is defeated by a rival, you may be even more pleased than usual when that rival team is subsequently beaten (Leach, Spears, \& Manstead, 2014). Thus, schadenfreude is more likely when recent experiences relating to the other person or group have made you feel inferior. More generally, schadenfreude depends on relative perceptions of own status in relation to the status of another person or group.

Schadenfreude research provides clear examples of how emotions can depend on interpersonal and intergroup dynamics. Studies are beginning to move beyond vignettes and to deploy more directly involving manipulations. The next step is to investigate how schadenfreude functions in real-world unfolding contexts and how its effects on allies and rivals, ingroup and outgroup members play out in interpersonal and intergroup settings (e.g., Feyaerts \& Oben, 2014; Fischer, 2014).

Although focusing on specific social emotions such as schadenfreude generates important insights, it also raises questions about the generality of any conclusions. For example, which aspects of schadenfreude arise from the particular characteristics of this emotion, and which depend on features and dimensions shared with other emotions? In methodological terms, these issues make it important to include appropriate comparison emotions in control conditions. At the conceptual level, there is the issue of how tightly schadenfreude itself should be defined (e.g., Leach et al., 2014) and whether it should be treated as a discrete emotion in its own right, with specific characteristics that distinguish it from apparently related phenomena such as gloating. For example, Boecker, Likowski, Pauli, and Weyers (in press) found that the same facial muscles were activated during both schadenfreude and joy experiences in response to TV clips of soccer penalty shots.

\section{Appraisal as a Social Process}

How do people arrive at the relational meanings associated with specific emotions? Appraisal researchers agree that a range of different perceptual and cognitive operations may be involved (e.g., Moors, 2013). Recent research has made advances in detailing some of appraisal's different instantiations, by accessing and manipulating some of the relevant mental operations (e.g., Moors, 2010; Tong, Tan, \& Tan, 2013) and exploring mathematical functions that might provide more accurate explanations of appraisal-emotion relations (e.g., Meuleman \& Scherer, 2013; Tong \& Tay, 2011).

Most studies of appraisal operations focus on intrapsychic aspects of the relational process. They pay less attention to the role of the "external" world and the other people in it. Campos and Stenberg (1981) distinguished individual appraisal from "social appraisal of how another individual is reacting to the event" (p. 275). Their basic idea was that individuals take into account other people's orientations to what is happening in addition to their own. This implies that what other people are doing can be seen as a constituent of a more extended, socially distributed appraisal process (Lewis, 1996; Parkinson, 2001).

Manstead and Fischer (2001) formalized the concept of social appraisal to cover situations in which relational meanings depend on other people's perceived evaluations. For example, extending research on social referencing in early development (e.g., Sorce, Emde, Campos, \& Klinnert, 1985), Parkinson, Phiri, and Simons (2012) showed that adults made less risky decisions when a friend expressed more anxiety via a video link, suggesting that appraisals depend on the perceived appraisals of others.

Social appraisal is not simply about resolving informational ambiguity about the personal significance of events. Other people's reactions also help to establish norms for emotion and action. Manstead and Fischer (2001) give the example of gauging a companion's reaction when hearing a potentially offensive joke. Similarly, van der Schalk, Kuppens, Bruder, and Manstead (2015) showed that participants who saw another person express regret about a decision to be fair in a resourceallocation game anticipated regret themselves and subsequently made less fair allocations. Lelieveld et al. (2013) found that participants' offers in an ultimatum game were higher when a supposedly disappointed other player was a member of a shared ingroup. Mediation analysis suggested that the ingroup member's disappointment caused participants to feel guilty about exploiting his or her apparent weakness. In other words, communicated disappointment can activate normative concerns about appropriate behavior.

E. R. Smith (1993) argued that appraisals assess the relevance of what is happening for social as well as personal identities. In other words, events concerning groups to which we belong can affect us emotionally even when they bring no direct consequences for us as individuals. Thus, we may feel guilt about misdemeanors committed by other group members even when they happened in the distant past (Branscombe \& Doosje, 2004). Research into group-based appraisals is an important growth area in current social psychology, and studies are investigating an ever wider range of emotions including pride (Sullivan, 2014), schadenfreude (Leach et al., 2014), and nostalgia (Wildschut, Bruder, Robertson, van Tilburg, \& Sedikides, in press). 
Few studies have directly investigated the connections between social appraisal and group-based emotions (see Bruder, Fischer, \& Manstead, 2014; Parkinson, 2011a). Studies of group-based emotions usually manipulate group identification at an individual level (e.g., by making relevant social identities more or less salient; Kuppens, Yzerbyt, Dandache, Fischer, $\&$ van der Schalk, 2013). Studies of social appraisal sometimes manipulate social identity (e.g., Lelieveld et al., 2013) but rarely explore how group members' appraisals converge or diverge over time during social interaction. Even studies explicitly investigating relations between group members' emotions (e.g., Barsade, 2002; Sy \& Choi, 2013) pay little attention to the role of social appraisal in the consolidation of group affect. The time is ripe for integrating insights across these areas.

\section{Explaining Social Effects of Emotion}

Studies of social appraisal provide examples of how emotions affect other people. But what specific processes explain these effects? Recently, social psychologists have made good progress in specifying some of the possibilities. In this section, we consider evidence relating to inferential and cuing processes relating to social appraisal, emotion contagion, mimicry, and other embodied mediators.

\section{Reverse Appraisal}

Social appraisal implies that people take other people's emotions into account when appraising what is happening, but precisely what information do they extract from those emotions, and how does it affect their own reactions? One possible answer is that people draw on their knowledge of appraisal-emotion associations to make inferences about the other person's appraisal (Hareli, 2014). These inferences in turn may influence their own appraisals, emotions, or behavior.

De Melo, Carnevale, and Gratch (2014) proposed that interpersonal effects of expressed emotion on cooperative behavior in Prisoner's Dilemma games depend on exactly this kind of process, which they term "reverse appraisal." When the other player expresses anger, participants infer that he or she is dissatisfied and directing blame externally (Lazarus, 1991), which is incompatible with cooperative intentions. Because they believe the other player is unlikely to cooperate, participants are less likely to cooperate themselves (Balliet \& van Lange, 2013).

Reverse appraisal also implies that interpersonal effects of facial expressions are context-dependent. For example, participants playing against an agent who smiled after cooperating inferred that cooperation was conducive to that agent's goals and were therefore more likely to reciprocate. By contrast, participants playing against an agent who smiled after defecting inferred that defection was conducive to that player's goals and were therefore less likely to cooperate. Arguably, playing a mixedmotive game remotely with an artificial agent maximizes the necessity for explicit inferences about that agent's programmed intentions. Indeed, de Melo et al. (2014) acknowledge that reverse appraisal is not the only possible process explaining emotion's interpersonal effects across all tasks. Other studies have shown that different mediators and effects may operate depending on whether interaction is with friends or strangers, and whether there is direct contact between participants in real time (e.g., Bruder, Dosmukhambetova, Nerb, \& Manstead, 2012).

\section{Gaze-Cued Appraisal}

It is well established that someone else's gaze can direct your attention towards objects in the environment (joint attention; e.g., Baron-Cohen, 1995). To the extent that emotions are associated with patterns of gaze towards or away from objects, they can have relatively direct effects on other people by influencing their attention. Bayliss, Frischen, Fenske, and Tipper (2007) also found that gaze direction may moderate the effects of another person's emotion expression on evaluations of objects. In their studies, disgust faces associated with visual stimuli led to less positive evaluations but only if their eyes were directed towards rather than away from those stimuli. Mumenthaler and Sander (2012) obtained comparable effects on the perception of facial expression stimuli. In particular, an "anger" face gazing at a target "fear" face made it more likely that participants labelled the target face as fear. In other words, participants seemed better able to perceive emotional meanings in faces when presented in a plausible interpersonal context. Because fear can be a response to someone else's anger, an angry expression directed at the target face seemed to cue the perception of fear in that target. These results may show that some forms of social appraisal can operate without any explicit inferences. If so, gaze-cued appraisal represents another distinct process that might mediate some of the social effects of emotion.

\section{Emotion Contagion}

Emotion contagion implies that emotions can spread like diseases around the social world. The term has been used to cover a wide range of possible processes (see Elfenbein, 2014). One of the most influential formulations refers to "primitive emotion contagion" (Hatfield, Cacioppo, \& Rapson, 1994), in which people automatically mimic each other's facial expressions and bodily postures, and interoceptive feedback from these reactions in turn produces corresponding emotions.

Although emotion contagion continues to be a popular focus of social psychological research (e.g., Dezecache et al., 2013; Sy \& Choi, 2013), ${ }^{3}$ there is little direct evidence for operation of the specific mimicry-feedback-emotion sequence (see Parkinson, 2011b). Instead, many studies find indirect evidence for contagion by ruling out other more explicit mediators of interpersonal emotion transfer (e.g., Gump \& Kulik, 1997; Parkinson \& Simons, 2009). Obviously, this does not confirm the specific nature of the nonexplicit process that is ruled in.

\section{Embodied Processes}

Many contemporary approaches to contagion make no assumption that the process is mediated specifically by mimicked facial 
or bodily responses (e.g., Neumann \& Strack, 2000). Some theorists assume that perception of someone else's expressive behavior directly activates the same brain regions that are activated during expression rather than perception, with no need for the expression itself to run off in order to generate the relevant internal signals (e.g., Damasio, 1994). Others argue that perception of others' emotions is not an abstract and amodal representation process in the first place (Barsalou, 1999) and instead involves running internal simulations of the relevant muscle movements (e.g., Niedenthal, Mermillod, Maringer, \& Hess, 2010). The simulation process then makes the relevant emotion concept more accessible, potentially influencing perception, emotion, and behavior (e.g., Rychlowska et al., 2014).

A number of recent studies have investigated embodied aspects of emotion perception. Interestingly, embodied effects of exposure to expressions do not seem to involve direct mimicry but rather reflect the implicitly perceived meaning of the expressions (e.g., Hess, Houde, \& Fischer, 2014). Hawk, Fischer, and van Kleef (2012) found that the extent to which participants responded to emotion-specific vocal stimuli with facial expressions associated with the same emotions positively predicted their ability to reproduce and recognize these sounds, and made it more likely that they would feel a corresponding emotion. These findings implicate cross-channel associations between embodied responses to emotions, but also raise questions about whether these associations depend on experience with expressing these emotions, or on more direct mutual constraints between vocal and facial aspects of expression during production.

\section{Integrated Models}

It seems that a range of potential processes may account for social effects of emotion. This raises the question of what factors determine which process is most influential. Research inspired by the EASI (emotions as social information) model (e.g., van Kleef, 2014) has made advances in specifying variables that make different kinds of processes more likely.

EASI distinguishes two broadly defined ways in which emotions exert interpersonal influence. The first inferential route involves participants using other people's emotions as evidence that helps them to arrive at decisions about how to act (e.g., reverse appraisal). The second route involves noninferential "affective reactions." These might include emotion contagion, embodied responses, and emotional forms of empathy.

What determines whether someone else's emotion activates inferential or affective processes? EASI focuses on two moderating factors: depth of information processing and perceived appropriateness of the other person's emotion. The first moderator is familiar from other dual-process models that postulate distinctions between higher level cognitively demanding mental operations such as deliberation or systematic processing, and lower level relatively automatic reactions based on associations, cues, or heuristics (see E. R. Smith \& de Coster, 2000). These models consistently make the plausible prediction that more resource-demanding processes are more likely when the individual has sufficient cognitive resources to perform them (and sufficient motivation to use those resources).
Moderating effects of appropriateness are more complicated. The idea is that emotions that are perceived as inappropriate invoke affective reactions that tend to override inferential effects. Conversely, emotions that are perceived as appropriate carry more direct and consistent inferential implications. For example, van Kleef and Côté (2007) showed that high-power negotiators reacted with stronger revenge-related feelings and made smaller concessions when their negotiation partner expressed anger that conflicted with an active display rule than when there was no display rule. Low-power negotiators had similar emotional reactions but their concessions were similar under both display-rule conditions, presumably because they did not feel able to enact their desire for revenge.

EASI's focus on only two possible routes of social influence determined by only two classes of moderator may be overrestrictive. Further elaboration of the theory will require deployment of a wider range of manipulations and measures in controlled and more realistic settings. Recent work shows that when and how an emotion is expressed may determine its emotional effects (Steinel, van Kleef, \& Harinck, 2008). For example, Sinaceur, Adam, van Kleef, and Galinsky (2013) found that a target whose emotions oscillated unpredictably between anger and happiness solicited more concessions than one who was consistently angry.

The assumption that both inferential and affective processes are triggered by "social information" about the other person's emotions may also be problematic. Most studies of social effects of emotion in bargaining, decision-making, and persuasion specifically present participants with information intended to convey what emotion the other person is experiencing (e.g., anger vs. sadness or disappointment) rather than putting participants in direct contact with another person expressing that emotion. But do emotions only exert social effects by virtue of their categorical meaning? When someone is getting angry with you here and now, does your reaction only depend on recognizing (implicitly or explicitly) that they are getting angry? Or do the separate components of their growing anger (the raised voice, focused stare, or bodily agitation) induce more direct lower level adjustment that need not depend on their perceived status as symptoms of emotion? In our view, some embodied responses to other people's emotions operate in this way, helping to explain how emotions' social effects developed in the first place. Emotions have interpersonal effects on infants before those infants have learned to categorize their meaning or infer appraisals. Similarly, emotions probably had social effects on early hominids before those hominids developed representational systems for categorizing them.

Communicative approaches to emotion and expression (e.g., Fridlund, 1994; Parkinson, 1995) also present potential issues for EASI. For example, recent work by Hess and Fischer (e.g., 2013) suggests that people mimic other people's facial expressions not as a direct reaction to the information transmitted by that expression, but as an active affiliative response intended to convey empathy or solidarity. In other words, expression seems to be regulated in order to achieve interpersonal effects. 


\section{Social Motives for Emotion Regulation}

Having considered how emotions influence other people, we turn to the question of how people influence their own and other people's emotions. Emotion regulation has become a central topic within social psychology, largely due to the influence of Gross's (e.g., 2015) process model. Research has focused on the different stages of an emotion episode that are targeted when people try to change or maintain their emotions. For example, antecedent-focused regulation may involve avoiding situations that we believe will make us anxious (situation selection), or changing our negative interpretation of what is happening by "looking on the bright side" or "seeing the silver lining" (reappraisal), and consequence-focused regulation may involve taking deep breaths to reduce our symptoms of physiological arousal, or trying to conceal our expression of panic (expressive suppression).

Originally, emotion-regulation research focused mainly on people's attempts to make themselves feel better, but researchers increasingly acknowledge that people sometimes regulate their emotions in a negative direction (Niven, Totterdell, \& Holman, 2009; Parrott, 1993). Tamir, Ford, and Gilliam (2013) found evidence for instrumental rather than hedonistic motives for emotion regulation, which may encourage people to increase the intensity of their negative emotions, or decrease the intensity of their positive emotions. For example, we may attempt to contain our excitement about an upcoming event because we need to stay focused, or we may work ourselves up into an angry state to prepare ourselves for a sports contest (Lane, Beedie, Devonport, \& Stanley, 2011).

An important set of motives for down-regulating positive emotions concerns our relations with other people. For example, it has long been recognized that different societies have different norms about the appropriateness of certain facial expressions in particular social contexts (e.g., Ekman, 1972). Some of these display rules encourage the expression of less positive emotions in the presence of certain audiences or addressees. For example, politeness may lead members of some cultures to suppress their expression of joy following victory if the vanquished opponents or supporters of those opponents are present (e.g., Kalokerinos, Greenaway, Pedder, \& Margetts, 2014). Upregulation of negative expressions is also encouraged in some contexts. For example, parents may feel obliged to work up their expression of anger when disciplining misbehaving children.

Inspired by Hochschild's (1983) seminal work, social psychologists have also been interested in the "feeling rules" that motivate emotional labor in interactions between service personnel and clients. In certain organizational contexts, these may lead employees to work up their experience of negative emotional states in order to exert social influence on others (e.g., Barber, Grawitch, Carson, \& Tsouloupas, 2011). For example, debt collectors, teachers, and police officers may use anger as an intimidation strategy. Apparently, then, people regulate their emotions because of their instrumental effects, including effects on other people's emotions (e.g., anger intimidates by inducing fear in others). In other words, intrapersonal emotion regulation may help with interpersonal emotion regulation.
Zaki and Williams (2013) distinguish two possible meanings of interpersonal emotion regulation. "Intrinsic interpersonal emotion regulation" involves interacting with other people in order to improve your own emotions, as might happen when we share our emotions with other people (e.g., Rimé, 2007) or seek their company when feeling anxious (e.g., Schachter, 1959). The more common ("extrinsic") formulation of interpersonal emotion regulation involves doing things in order to change other people's emotions. Sometimes, this also involves intrapersonal (or intrinsic interpersonal) emotion regulation, as happens when we try to contain our anxiety in order to stop our companions from feeling more worried (Parkinson \& Simons, 2012). Regulating someone else's emotions also seems to affect our own feelings (Niven, Totterdell, Holman, \& Headley, 2012), suggesting that people might be able to use interpersonal regulation as an indirect form of intrapersonal regulation. Indeed, in ongoing interactions, making someone else feel better by expressing positive feelings might also mean that their more positive feelings make you feel better too (e.g., Kim \& Yoon, 2012). As Zaki and Williams (2013) argue, distinguishing different forms of interpersonal emotion regulation may help us to understand the links with related areas of research, such as social support seeking and receipt (e.g., Bolger \& Amarel, 2007), corumination (e.g., Rose, Carlson, \& Waller, 2007), and coregulation in romantic relationships (e.g., Butler \& Randall, 2012).

\section{Where Next?}

Although no single overarching theory guides social psychological research in emotion, most researchers adopt (or adapt) a methodological approach inherited from cognitive and experimental psychology. Controlled experiments in which individual participants are presented with socially relevant materials continue to be the norm. Such methodologies tend to sustain and reproduce a theoretical view of emotions as reactive and intrapsychic.

Since the late 1960 s, a number of major and minor crises of confidence have unsettled commitment to experimental approaches to our discipline. Clearly some of the phenomena that social psychologists find interesting do not reflect fixed and uncontrollable laws of human nature but may vary from culture to culture (e.g., Boiger, Mesquita, Uchida, \& Barrett, 2013), era to era (e.g., Gergen, 1973), and indeed moment to moment, depending on contextual variation or fluctuating social relations. Pinning down facts requires acknowledgement of contingency and context-dependence (Schlenker, 1974). Indeed much of the progress in many areas of social psychology, including the social psychology of emotion, involves discovering exceptions to general principles that then lead to more inclusive moderated models in which different processes are said to apply under different circumstances. Because some of the moderators are subtle and evanescent, key findings are not always replicable. Because journals privilege clear findings produced using established methods, reporting becomes more selective. All this can lead to cynical manipulation and exploitation of the perceived gatekeeping strategies shaping academic career progression, especially in 
institutions and societies where quantitative and consensual evidence of success attracts resources (see Reicher, 2011). There is a risk that proposed safeguards against the worst consequences of these pressures (frauds and partial truths) entrench even more rigid methodological constraints, rather than promoting pluralism.

There is nevertheless cause for optimism in the progress of the social psychology of emotion, as we hope the preceding sampling of recent research demonstrates. Increasing acknowledgement that emotions have social causes, social effects, and social functions, that they regulate and are regulated by social interactions, is beginning to lead social psychologists beyond individual tasks and sometimes out of the laboratory entirely (Cunningham et al., 2013). The growing availability of mobile recording technologies and sophisticated statistical techniques for dyadic, multilevel, and overtime analysis (e.g., Butler, 2011) helps to allay some of the fears of overcomplication when considering the web of interlocking dynamic social processes that unfold around emotional life. The fact that people interact and share emotions using increasingly mobile media opens up a range of new research avenues. Face-to-face interaction may begin to seem like a special case that has no priority in our thinking. We will always be constrained by available methods, but sometimes those methods allow us to see outside the box.

Already, relationship researchers are examining how two people's emotional expressions can entrain each other or diverge under different conditions (e.g., Randall, Post, Reed, \& Butler, 2013). Studies of group processes have also begun to examine the dynamics of intragroup affect dependencies (e.g., Sy \& Choi, 2013). Such research may yield specific hypotheses that are worth testing in more controlled settings using more traditional methods, but may also open up the social psychology of emotion, so that it no longer regards individual reactions as the primary phenomenon of interest. Emotions are attached to objects with cultural meanings, and unfold as part of interpersonal, intragroup, and intergroup interactions in a wider social world (Mesquita \& Boiger, 2014; Parkinson, Fischer, \& Manstead, 2005). It is this world that should be of most interest to us all.

\section{Declaration of Conflicting Interests}

The author(s) declared no potential conflicts of interest with respect to the research, authorship, and/or publication of this article.

\section{Notes}

1 A large and growing social psychological literature concerning facial expression is clearly relevant to some of this article's concerns. However, this research was reviewed in a recent special section of this journal, so we say relatively little about it here (see Parkinson, 2013).

2 Because of space restrictions, our article also excludes important recent work in the cultural psychology of emotion, which takes us beyond the familiar but crude distinction between individualist and collectivist societies (e.g., Boiger, Mesquita, Tsai, \& Markus, 2012), and the common assumption that cultural variation merely reflects differences in norms and representations (e.g., Boiger et al., 2013).

3 We have not included the famous (or infamous) study by Kramer, Guillory, and Hancock (2014) on this list, mainly because we believe that it is inaccurate to claim that it addresses "emotion contagion" in its usual senses. Participants evidently responded to unpleasant information transmitted by Facebook ${ }^{\mathrm{TM}}$ by sending out more unpleasant information themselves. The reported results do not allow us to determine whether participants' (presentations of) emotions were influenced by the bad events described in other people's postings or by their perceptions of the other person's feelings.

\section{References}

Algoe, S. B. (2012). Find, remind, and bind: The functions of gratitude in everyday relationships. Social and Personality Psychology Compass, $6,455-469$.

Allport, G. W. (1954). The historical background of social psychology. In G. Lindzey \& E. Aronson (Eds.), Handbook of social psychology (Vol.1, pp. 1-46). New York, NY: Random House.

Balliet, D., \& van Lange, P. A. M. (2013). Trust, conflict, and cooperation: A meta-analysis. Psychological Bulletin, 139, 1090-1112.

Barber, L. K., Grawitch, M. J., Carson, R. L., \& Tsouloupas, C. N. (2011). Costs and benefits of supportive versus disciplinary emotion regulation strategies in teachers. Stress and Health, 27, 173-187.

Baron-Cohen, S. (1995). The eye direction detector (EDD) and the shared attention mechanism (SAM): Two cases for evolutionary psychology. In C. Moore \& P. J. Dunham (Eds.), Joint attention: Its origins and role in development (pp. 41-59). Hillsdale, NJ: Lawrence Erlbaum.

Barsade, S. G. (2002). The ripple effect: Emotional contagion and its influence on group behavior. Administrative Science Quarterly, 47, 644675.

Barsalou, L. W. (1999). Perceptual symbol systems. Behavioral and Brain Sciences, 22, 577-609.

Bayliss, A. P., Frischen, A., Fenske, M. J., \& Tipper, S. P. (2007). Affective evaluations of objects are influenced by observed gaze direction and emotion expression. Cognition, 104, 644-653.

Boecker, L., Likowski, K., Pauli, P., \& Weyers, P. (in press). The face of schadenfreude: Differentiation of joy and schadenfreude by electromyography. Cognition and Emotion.

Boiger, M., Mesquita, B., Tsai, A. Y., \& Markus, H. R. (2012). Influencing and adjusting in daily emotional situations: A comparison of European and Asian American action styles. Cognition \& Emotion, 26, 332-340.

Boiger, M., Mesquita, B., Uchida, Y., \& Barrett, L. F. (2013). Condoned or condemned: The situational affordance of anger and shame in the United States and Japan. Personality and Social Psychology Bulletin, $39,540-553$.

Bolger, N., \& Amarel, D. (2007). Effects of social support visibility on adjustment to stress: Experimental evidence. Journal of Personality and Social Psychology, 92, 458-475.

Booker, S., \& Waite, B. M. (2005, May). Humilitainment? Lessons from "The Apprentice": A reality TV content analysis. Paper presented at the 17th Annual Convention of the American Psychological Society, Los Angeles, CA.

Branscombe, N. R., \& Doosje, B. (Eds.). (2004). Collective guilt: International perspectives. New York, NY: Cambridge University Press.

Brown, S., \& Stenner, P. (2009). Psychology without foundations: History, philosophy and psychosocial theory. London, UK: Sage.

Bruder, M., Dosmukhambetova, D., Nerb, J., \& Manstead, A. S. R. (2012). Emotional signals in nonverbal interaction: Dyadic facilitation and convergence in expressions, appraisals, and feelings. Cognition and Emotion, 26, 480-502.

Bruder, M., Fischer, A., \& Manstead, A. S. R. (2014). Social appraisal as a cause of collective emotions. In C. von Scheve \& M. Salmela (Eds.), Collective emotions (pp. 141-155). Oxford, UK: Oxford University Press.

Butler, E. A. (2011). Temporal interpersonal emotion systems: The "TIES" that form relationships. Personality and Social Psychology Review, 15, 367-393. 
Butler, E. A., \& Randall, A. K. (2012). Emotional coregulation in close relationships. Emotion Review, 5, 202-210.

Campos, J. J., \& Stenberg, C. (1981). Perception, appraisal, and emotion: The onset of social referencing. In M. E. Lamb \& L. R. Sherrod (Eds.), Infant social cognition: Empirical and theoretical contributions (pp. 217-314). Hillsdale, NJ: Erlbaum.

Cunningham, W. A., Dunfield, K. A., \& Stillman, P. E. (2013). Emotional states from affective dynamics. Emotion Review, 5, 344-355.

Damasio, A. (1994). Descartes' error: Emotion, reason, and the human brain. New York, NY: Putnam.

De Melo, C., Carnevale, P. J., \& Gratch, J. (2014). Reading people's minds from emotion expressions in interdependent decision making. Journal of Personality and Social Psychology, 106, 73-88.

Dezecache, G., Conty, L., Chadwick, M., Philip, L., Soussignan, R., Sperber, D., \& Grèzes, J. (2013). Evidence for unintentional emotional contagion beyond dyads. Plos One, 8, e67371. doi:10.1371/journal. pone. 0067371

Edwards, D. (1999). Emotion discourse. Cultural Psychology, 5, 271-291.

Ekman, P. (1972). Universals and cultural differences in facial expressions of emotion. In J. Cole (Ed.), Nebraska Symposium on Motivation (pp. 207-283). Lincoln: University of Nebraska Press.

Elfenbein, H. A. (2014). The many faces of emotion contagion: An affective process theory of affective linkage. Organizational Psychology Review, $4,1-37$.

Feather, N. T., Wenzel, M., \& McKee, I. R. (2012). Integrating multiple perspectives on schadenfreude: The role of deservingness and emotions. Motivation and Emotion, 37, 574-585.

Feyaerts, K., \& Oben, B. (2014). Tracing down schadenfreude in spontaneous interaction: Evidence from corpus linguistics. In W. W. van Dijk \& J. W. Ouwerkerk (Eds.), Schadenfreude: Understanding pleasure at the misfortune of others (pp. 275-291). Cambridge, UK: Cambridge University Press.

Fischer, A. H. (2014). Schadenfreude: Concluding notes. In W. W. van Dijk \& J. W. Ouwerkerk (Eds.), Schadenfreude: Understanding pleasure at the misfortune of others (pp. 304-311). Cambridge, UK: Cambridge University Press.

Fischer, A. H., \& Roseman, I. J. (2007). Beat them or ban them: The characteristics and social functions of anger and contempt. Journal of Personality and Social Psychology, 93, 103-115.

Fischer, A. H., \& van Kleef, G. A. (2010). Where have all the people gone? A plea for including social interaction in emotion research. Emotion Review, 2, 208-211.

Fridlund, A. J. (1994). Human facial expression: An evolutionary view. San Diego, CA: Academic Press.

Gergen, K. T. (1973). Social psychology as history. Journal of Personality and Social Psychology, 26, 309-320.

Giner-Sorolla, R. (2012). Judging passions: Moral emotions in persons and groups. New York, NY: Psychology Press.

Goetz, J. L., Keltner, D., \& Simon-Thomas, E. (2010). Compassion: An evolutionary analysis and empirical review. Psychological Bulletin, 136, 351-374.

Gross, J. J. (2015). Emotion regulation: Current status and future prospects. Psychological Inquiry, 26, 1-26.

Gump, B. B., \& Kulik, J. A. (1997). Stress, affiliation, and emotional contagion. Journal of Personality and Social Psychology, 72, 305-319.

Hareli, S. (2014). Making sense of the social world and influencing it by using a naïve attribution theory of emotions. Emotion Review, 6, 336343.

Hareli, S., \& Parkinson, B. (2008). What's social about social emotions? Journal for the Theory of Social Behavior, 38, 131-156.

Hatfield, E., Cacioppo, J. T., \& Rapson, R. L. (1994). Emotional contagion. New York, NY: Cambridge University Press.

Hawk, S. T., Fischer, A. H., \& van Kleef, G. A. (2012). Face the noise: Embodied responses to nonverbal vocalizations of discrete emotions. Journal of Personality and Social Psychology, 102, 796-814.
Hess, U., \& Fischer, A. (2013). Emotional mimicry as social regulation. Personality and Social Psychology Review, 17, 142-157.

Hess, U., Houde, S., \& Fischer, A. (2014). Do we mimic what we see or what we know? In C. von Scheve \& M. Salmela (Eds.), Collective emotions (pp. 94-107). Oxford, UK: Oxford University Press.

Hochschild, A. R. (1983). The managed heart: Commercialization of human feeling. Berkeley: University of California Press.

Jia, L., Tong, E. M. W., \& Lee, L. N. (2014). Psychological "gel" to bind individuals' goal pursuit: Gratitude facilitates goal contagion. Emotion, $14,748-760$

Kalokerinos, E. K., Greenaway, K. H., Pedder, D. J., \& Margetts, E. A. (2014). Don't grin when you win: The social costs of positive emotion expression in performance situations. Emotion, 14, 180-186.

Kim, E., \& Yoon, D. J. (2012). Why does service with a smile make employees happy? A social interaction model. Journal of Applied Psychology, 97, 1059-1067.

Kramer, A. D. I., Guillory, J. E., \& Hancock, J. T. (2014). Experimental evidence of massive-scale emotional contagion through social networks. Proceedings of the National Academy of Sciences of the United States of America, 111, 8788-8790.

Kreibig, S. D. (2010). Autonomic nervous system activity in emotion: A review. Biological Psychology, 84, 394-421.

Kuppens, T., Yzerbyt, V. Y., Dandache, S., Fischer, A. H., \& van der Schalk, J. (2013). Social identity salience shapes group-based emotions through group-based appraisals. Cognition and Emotion, 27, 1359-1377.

Lane, A. M., Beedie, C. J., Devonport, T. J., \& Stanley, D. M. (2011). Instrumental emotion regulation in sport: Relationships between beliefs about emotion and emotion regulation strategies used by athletes. Scandinavian Journal of Medicine \& Science in Sports, 21, e445-e451. doi:10.1111/j.1600-0838.2011.01364.x

Latané, B., \& Darley, J. M. (1968). Group inhibition of bystander intervention in emergencies. Journal of Personality and Social Psychology, 10, 215-221.

Lazarus, R. S. (1991). Emotion and adaptation. Oxford, UK: Oxford University Press.

Leach, C. W., Spears, R., \& Manstead, A. S. R. (2014). Situating schadenfreude in social relations. In W. W. van Dijk \& J. W. Ouwerkerk (Eds.), Schadenfreude: Understanding pleasure at the misfortune of others (pp. 200-216). Cambridge, UK: Cambridge University Press.

Lelieveld, G.-J., van Dijk, E., van Beest, I., \& van Kleef, G. A. (2013). Does communicating disappointment in negotiations help or hurt? Solving an apparent inconsistency in the social-functional approach to emotions. Journal of Personality and Social Psychology, 105, 605-620.

Lewis, M. D. (1996). Self-organising cognitive appraisals. Cognition and Emotion, 10, 1-25.

Manstead, A. S. R., \& Fischer, A. H. (2001). Social appraisal: The social world as object of and influence on appraisal processes. In K. R. Scherer, A. Schorr, \& T. Johnstone (Eds.), Appraisal processes in emotion: Theory, methods, research (pp. 221-232). New York, NY: Oxford University Press.

Mead, G. H. (1934). Mind, self, and society. Chicago, IL: University of Chicago Press.

Mesquita, B., \& Boiger, M. (2014). Emotions in context: A sociodynamic model of emotions. Emotion Review, 6, 298-302.

Meuleman, B., \& Scherer, K. (2013). Nonlinear appraisal modeling: An application of machine learning to the study of emotion production. IEEE Transactions on Affective Computing, 4, 398-411.

Moors, A. (2010). Automatic constructive appraisal as a candidate cause of emotion. Emotion Review, 2, 139-156.

Moors, A. (2013). On the causal role of appraisal in emotion. Emotion Review, 5, 132-140.

Mumenthaler, C., \& Sander, D. (2012). Social appraisal influences recognition of emotions. Journal of Personality and Social Psychology, 102, $1118-1135$. 
Neumann, R., \& Strack, F. (2000). Mood contagion: The automatic transfer of mood between persons. Journal of Personality and Social Psychology, 79, 211-223.

Niedenthal, P. M., Mermillod, M., Maringer, M., \& Hess, U. (2010). The simulation of smiles (SIMS) model: Embodied simulation and the meaning of facial expression. Behavioral and Brain Sciences, 33, 417-433.

Niven, K., Totterdell, P., \& Holman, D. (2009). A classification of controlled interpersonal affect regulation strategies. Emotion, 9, 498-509.

Niven, K., Totterdell, P., Holman, D., \& Headley, T. (2012). Does regulating others' feelings influence people's own affective well-being? Journal of Social Psychology, 152, 246-260.

Parkinson, B. (1995). Ideas and realities of emotion. London, UK: Routledge.

Parkinson, B. (2001). Putting appraisal in context. In K. R. Scherer, A. Schorr, \& T. Johnstone (Eds.), Appraisal processes in emotion: Theory, research, application (pp. 173-186). New York, NY: Oxford University Press.

Parkinson, B. (2011a). How social is the social psychology of emotion? British Journal of Social Psychology, 50, 405-413.

Parkinson, B. (2011b). Interpersonal emotion transfer: Contagion and social appraisal. Personality and Social Psychology Compass, 5, 428-439.

Parkinson, B. (2013). Contextualizing facial activity. Emotion Review, 5, 97-103.

Parkinson, B., Fischer, A., \& Manstead, A. S. R. (2005). Emotion in social relations: Cultural, group, and interpersonal processes. Philadelphia, PA: Psychology Press.

Parkinson, B., Phiri, N., \& Simons, G. (2012). Bursting with anxiety: Adult social referencing in an interpersonal Balloon Analogue Risk Task (BART). Emotion, 12, 817-826.

Parkinson, B., \& Simons, G. (2012). Worry spreads: Interpersonal transfer of problem-related anxiety. Cognition and Emotion, 26, 462-479.

Parrott, W. G. (1993). Beyond hedonism: Motives for inhibiting good moods and for maintaining bad moods. In D. M. Wegner \& J. W. Pennebaker (Eds.), Handbook of mental control (pp. 278-305). Englewood Cliffs, NJ: Prentice Hall.

Parrott, W. G. (2001). Emotions in social psychology: Volume overview. In W. G. Parrott (Ed.), Emotions in social psychology (pp. 1-19). New York, NY: Psychology Press.

Parrott, W. G., \& Smith, R. H. (1993). Distinguishing the experiences of envy and jealousy. Journal of Personality and Social Psychology, 64, 906-920.

Randall, A. K., Post, J. H., Reed, R. G., \& Butler, E. A. (2013). Cooperating with your romantic partner: Associations with interpersonal emotion coordination. Journal of Social and Personal Relationships, 30, 1072-1095.

Reicher, S. D. (2011). Promoting a culture of innovation: BJSP and the emergence of new paradigms in social psychology. British Journal of Social Psychology, 50, 391-398.

Reicher, S. D., \& Haslam, S. A. (2006). Rethinking the psychology of tyranny: The BBC Prison Study. British Journal of Social Psychology, $45,1-40$.

Rimé, B. (2007). Interpersonal emotion regulation. In J. Gross (Ed.), Handbook of emotion regulation (pp. 466-485). New York, NY: Guilford Press.

Rose, A. J., Carlson, W., \& Waller, E. M. (2007). Prospective associations of co-rumination with friendship and emotional adjustment: Considering the socioemotional trade-offs of co-rumination. Developmental Psychology, 43, 1019-1031.

Rychlowska, M., Cañadas, E., Wood, A., Krumhuber, E. G., Fischer, A., $\&$ Niedenthal, P. M. (2014). Blocking mimicry makes true and false smiles look the same. PLOS ONE, 9, e90876. doi:10.1371/journal. pone. 0090876

Sampson, E. E. (2008). Celebrating the other: A dialogic account of human nature. Chagrin Falls, OH: Taos Institute.
Schachter, S. (1959). The psychology of affiliation. Stanford, CA: Stanford University Press.

Schachter, S., \& Singer, J. E. (1962). Cognitive, social, and physiological determinants of emotional state. Psychological Review, 69, 379-399.

Schlenker, B. R. (1974). Social psychology and science. Journal of Personality and Social Psychology, 29, 1-15.

Sinaceur, M., Adam, H., van Kleef, G. A., \& Galinsky, A. D. (2013). The advantages of being unpredictable: How emotional inconsistency extracts concessions in negotiation. Journal of Experimental Social Psychology, 49, 498-508.

Smith, C. A., \& Ellsworth, P. C. (1985). Patterns of cognitive appraisal in emotion. Journal of Personality and Social Psychology, 48, 813-838.

Smith, E. R. (1993). Social identity and social emotions: Toward new conceptualizations of prejudice. In D. M. Mackie, D. Hamilton, \& D. Lewis (Eds.), Affect, cognition, and stereotyping: Interactive processes in group perception (pp. 297-315). San Diego, CA: Academic Press.

Smith, E. R., \& DeCoster, J. (2000). Dual-process models in social and cognitive psychology: Conceptual integration and links to underlying memory systems. Personality and Social Psychology Review, 4, $108-131$.

Smith, R. H. (2013). Schadenfreude and the dark side of human nature. Oxford, UK: Oxford University Press.

Smith, R. H., \& Kim, S. H. (2007). Comprehending envy. Psychological Bulletin, 133, 46-64.

Sorce, J. F., Emde, R. N., Campos, J., \& Klinnert, M. D. (1985). Maternal emotional signaling: Its effect on the visual cliff behavior of 1 year olds. Developmental Psychology, 21, 195-200.

Steinel, W., van Kleef, G. A., \& Harinck, F. (2008). Are you talking to me?! Separating the people from the problem when expressing emotions in negotiation. Journal of Experimental Social Psychology, 44, 362-369.

Stephan, W. G. (2014). Intergroup anxiety: Theory, research, and practice. Personality and Social Psychology Review, 18, 239-255.

Sullivan, G. B. (2014). Collective pride, happiness, and celebratory emotions: Aggregative, network, and cultural models. In C. von Scheve \& M. Salmela (Eds.), Collective emotions (pp. 266-280). Oxford, UK: Oxford University Press.

Sy, T., \& Choi, N. M. (2013). Contagious leaders and followers: Exploring multi-stage mood contagion in a leader activation and member propagation (LAMP) model. Organizational Behavior and Human Decision Processes, 122, 127-140.

Tamir, M., Ford, B. Q., \& Gilliam, M. (2013). Evidence for utilitarian motives in emotion regulation. Cognition and Emotion, 27, 483-491.

Tangney, J. P., \& Dearing, R. L. (2002). Shame and guilt. New York, NY: Guilford.

Tong, E. M. W. (2015). Differentiation of 13 positive emotions by appraisals. Cognition and Emotion, 29, 484-503.

Tong, E. M. W., Tan, D. H., \& Tan, Y. L. (2013). Can implicit appraisal concepts produce emotion-specific effects? A focus on unfairness and anger. Consciousness and Cognition, 22, 449-460.

Tong, E. M. W., \& Tay, K. L. H. (2011). S-shaped appraisal-emotion relationships: The role of neuroticism. Social Psychological and Personality Science, 2, 487-493.

Van der Schalk, J., Kuppens, T., Bruder, M., \& Manstead, A. S. R. (2015). The social power of regret: The effect of social appraisal and anticipated emotions on fair and unfair allocations in resource dilemmas. Journal of Experimental Psychology: General, 144, 151-157.

Van Dijk, W. W., \& Ouwerkerk, J. W. (2014). Introduction to schadenfreude. In W. W. van Dijk \& J. W. Ouwerkerk (Eds.), Schadenfreude: Understanding pleasure at the misfortune of others (pp. 1-13). Cambridge, UK: Cambridge University Press.

Van Dijk, W. W., Ouwerkerk, J. W., van Koningsbruggen, G. M., \& Wesseling, Y. M. (2012). "So you wanna be a pop star?" Schadenfreude following another's misfortune on TV. Basic and Applied Social Psychology, 34, 168-174. 
Van Dijk, W. W., Ouwerkerk, J. W., Wesseling, Y. M., \& van Koningsbruggen, G. M. (2011). Towards understanding pleasure at the misfortunes of others: The impact of self-evaluation threat on schadenfreude. Cognition and Emotion, 25, 360-368.

Van Kleef, G. A. (2014). Understanding the positive and negative effects of emotional expressions in organizations: EASI does it. Human Relations, 67, 1145-1164.

Van Kleef, G. A., \& Côté, S. (2007). Expressing anger in conflict: When it helps and when it hurts. Journal of Applied Psychology, 92, 1557-1569.

Wetherell, M. S. (2012). Affect and emotion: A new social science understanding. New York, NY: Sage.
Wildschut, T., Bruder, M., Robertson, S., van Tilburg, W. A., \& Sedikides, C. (2014). Collective nostalgia: A group-level emotion that confers unique benefits on the group. Journal of Personality and Social Psychology, 107(5), 844.

Worthy, D. A., Byrne, K. A., \& Fields, S. (2014). Effects of emotion on prospection during decision-making. Frontiers in Psychology, 5, 591. doi:10.3389/fpsyg.2014.00591

Zadro, L., Williams, K. D., \& Richardson, R. (2004). Riding the "O" train: Comparing the effects of ostracism and verbal dispute on targets and sources. Group Processes and Interpersonal Relations, 8, 125-143.

Zaki, J., \& Williams, W. C. (2013). Interpersonal emotion regulation. Emotion, 13, 803-810. 